\title{
Haemolytic activity of the 'Streptococcus milleri group' and relationship between haemolysis restricted to human red blood cells and pathogenicity in $S$. intermedius
}

\author{
J. A. JACOBS, C. S. SCHOT* and L. M. SCHOULS*
}

Department of Medical Microbiology, University Hospital of Maastricht, PO Box 5800, 6202 AZ Maastricht and * Research Laboratory for Infectious Diseases, National Institute of Public Health and the Environment, PO Box 1, 3720 BA Bilthoven, The Netherlands

A collection of 297 clinically documented 'Streptococcus milleri' strains, identified to the genotype level by 16S rRNA gene hydridisation, was screened for haemolysis of human and animal red blood cells. Forty-nine strains $(65 \%)$ of the $S$. intermedius genotype displayed haemolysis restricted to human blood; they were named 'exclusive human haemolytic' (EHH) S. intermedius strains. The 26 remaining $S$. intermedius strains were named S. intermedius non-EHH strains. Quantitative studies on the haemolysis indicated that intermedilysin was the factor involved. The S. intermedius EHH strains represented the $\mathrm{S}$. intermedius phenotype, whereas the $\mathrm{S}$. intermedius non-EHH strains were phenotypically characteristic of S. constellatus. The complete 16S rRNA sequences of the S. intermedius EHH strains exhibited identity with S. intermedius strains ATCC 27335 (= NCDO 2227, NCTC 11324); the 16S rRNA sequences of the S. intermedius non-EHH strains were identical to S. constellatus strain ATCC 27823 (=NCDO 2226, NCTC 11325) except for positions 228 and 229 that carried an S. intermedius sequence signature. The $16 \mathrm{~S}$ sequence similarities between the non-EHH strains and the S. constellatus and the S. intermedius type strains were $99.5 \%$ and $98.6 \%$, respectively. $\mathrm{Hybridisations}$ of the complete 16S rRNA genes with oligonucleotide probes indicated a 16S rRNA homogeneity within the S. intermedius $\mathrm{EHH}$ and the non-EHH strains respectively. The $\mathrm{S}$. intermedius $\mathrm{EHH}$ strains were isolated most frequently from infection- and abscess-related specimens. The present data emphasise the genetic variability within the $S$. constellatus species and redefine the $S$. intermedius species as a homogeneous group at the 16S rRNA level.

\section{Introduction}

Streptococcus intermedius, S. anginosus and S. constellatus belong to the 'Streptococcus milleri' group (SMG) that forms a separate phylogenetic group recently designated as the 'anginosus group' [1,2]. SMG strains are notorious because of their ability to cause purulent infections and abscesses and are known for their phenotypic heterogeneity, which makes them difficult to identify $[3,4]$. A previous study described a collection of SMG strains that were identified to the $16 S$ rRNA genotype level by hybridisation of the PCRamplified partial 16S rRNA gene with species-specific

Received 16 Feb. 1999; accepted 7 June 1999.

Corresponding author: Dr J. A. Jacobs (e-mail: JJA@msazm-3.azm.nl). oligonucleotide probes. These probes were homologous to the 213-231-bp regions of the 16S rRNA sequences of the type strains S. anginosus ATCC $33397^{\top}$, S. constellatus ATCC $27823^{\top}$ and S. intermedius ATCC $27335^{\top}$. That study revealed a distinct 165 rRNA ribosomal population that reacted with both the $S$. intermedius- and S. constellatus-specific probes: these strains, referred to as ' $\mathrm{Cl}$ strains', were most closely related to S. constellatus strain ATCC $27823^{\top}$ [5].

Although SMG strains are part of the 'viridans streptococci', they may exhibit all three types of haemolysis $(\alpha-, \beta$ - or $\gamma$-haemolysis). Several studies reported $\beta$-haemolytic 'S. milleri' strains to be associated with purulent disease more frequently than non-haemolytic strains $[6,7]$, but this association was not found by others [8]. A study of 499 SM G clinical 
strains consecutively isolated irrespective of their haemolytic behaviour found that non-haemolytic strains were isolated more frequently from abscess-related specimens than $\beta$-haemolytic strains [9]. Furthermore, it found that the $S$. intermedius phenotype was proportionally more associated with infection and abscesses than the $\mathrm{S}$. anginosus and $\mathrm{S}$. constellatus phenotypes. The data also confirmed the findings of Whiley and co-workers [10] who reported that the majority of $\mathrm{S}$. intermedius strains are non-haemolytic on sheep blood agar. These findings apparently dispute the assumed association between $\beta$-haemolysis and pathogenicity. Recently, Nagamune and co-workers identified a cytotoxin in an $\mathrm{S}$. intermedius strain, which they called intermedilysin [11]. They demonstrated that intermedilysin was strongly haemolytic against human red blood cells (RBC) but did not lyse RBC from non-primates. The authors raised the question as to whether intermedilysin analogues were expressed by the other SMG species, but no information on this subject has been reported to date. Moreover, it is not yet known if all S. intermedius strains produce this enzyme.

This study investigated the expression of the haemolytic activities of the different SMG species against RBC of human and animal origin and correlated the expression of haemolytic activity against human RBC with the clinical significance of the strains. In addition, it investigated the genotypic heterogeneity amongst strains that exhibited different haemolytic patterns against human and animal RBC.

\section{$M$ aterials and methods}

Bacterial strains, phenotypic and genotypic identification and clinical significance

The streptococci studied were isolated from clinical specimens submitted to the microbiology laboratory of the University Hospital of $M$ aastricht. Their phenotypic and genotypic identification, site of origin and clinical significance have been described previously [5]. B riefly, streptococci were included in the study if they were identified as 'S. milleri' by the API 20 Strep system supplied with the database 4.0 (bioM érieux, MarcyI'Etoile, France). Phenotypic species identification was performed according to the scheme described by Whiley and co-workers [12]: strains were tested for production of glycosidase enzyme activities with 4methylumbelliferyl-linked fluorogenic substrates (Sig$\mathrm{ma}$ ) and for production of hyaluronidase by a plate assay [13]. Genotypic identification was performed in a line blot assay: PCR-amplified 165 ribosomal RNA gene was hybridised with species-specific 5'-biotinylated oligonucleotide probes homologous to the 213231-base region of the 16S rRNA gene sequences of the type strains $\mathrm{S}$. anginosus ATCC $33397^{\top}$ (= NCTC 10713), S. constellatus ATCC $27823^{\top}$ (= NCDO 2226, NCTC 11325) and S. intermedius ATCC $27335^{\top}$
(= NCD 0 2227, NCTC 11324). Strains were assigned to broad clinical categories (abscess-related, infectionrelated and questionable clinical significance) based upon the opinion of the clinician treating the patient [14].

The isolates were stored at $-70^{\circ} \mathrm{C}$ on porous beads in a cryopreservative (Microbank, Pro-Lab Diagnostics, Richmond Hill, Ont, Canada). Before inclusion in the study, they were retrieved, checked for purity and subcultured. Two strains were not recoverable. All 75 strains genotypically identified as S. intermedius were included in the study, and $101 \mathrm{~S}$. anginosus strains were randomly selected from the collection.

In the previous study, the PCR-amplified 165 rRNA genes of 41 SMG strains hybridised with the probes directed to the 213-231 base region of the 16S rRNA genes of both the S. constellatus ATCC $27823^{\top}$ and the S. intermedius ATCC $27335^{\top}$ type strains [5]. These ' $\mathrm{Cl}$ strains' were presently grouped together with the 80 genotypic $\mathrm{S}$. constellatus strains, to which they are most closely related. Reference strains included in the collection were the type strains $S$. anginosus ATCC $33397^{\top}$, S. constellatus ATCC $27823^{\top}$ and S. intermedius ATCC $27335^{\top}$.

\section{Detection and characterisation of haemolytic activity}

For the qualitative detection of haemolytic activity, fresh RBC obtained from sheep, cow, horse, pig and rabbit were kindly provided by $\mathrm{Dr}$ van den Boogaard (Central Experimental Animal Facilities, Maastricht University, The Netherlands). Human RBC of group 0 $\mathrm{Rh}^{+}$were obtained from one of the authors (J.A.J.). RBC were washed three times with phosphate-buffered saline (PBS) pH 7.4, and added (2.5\% v/v) to Blood A gar Base No. 2 (Oxoid); $20 \mathrm{ml}$ were dispensed into polystyrene Petri dishes. The plates were left at room temperature overnight to dry and then inoculated with $10^{4} \mathrm{cfu} / \mathrm{spot}$ with a multipoint inoculator (Denley, Sussex) and incubated in air with $\mathrm{CO}_{2} 7 \%$ at $35^{\circ} \mathrm{C}$. After incubation for $18 \mathrm{~h}$, the colonies were stabbed with a sterile toothpick and incubated in $\mathrm{CO}_{2} 7 \%$ at $35^{\circ} \mathrm{C}$ for another $24 \mathrm{~h}$. Haemolysis was read by observation of the subsurface growth, both $\alpha$ - and $\gamma$ haemolysis were recorded as 'non-haemolytic'. The effect of hot and cold incubation on the haemolysis of human RBC was studied on 12 strains by incubating inoculated blood plates at $35^{\circ} \mathrm{C}$ for $24 \mathrm{~h}$, and subsequently transferring them to $4^{\circ} \mathrm{C}$ overnight. Phospholipase enzyme activities were assayed with Egg Yolk Emulsion (Oxoid $5 \% \mathrm{v} / \mathrm{v}$ ) added to Blood Agar Base No. 2.

For quantitative assessment of the haemolytic activities of the culture supernatant fluids, streptococci were grown in $10 \mathrm{ml}$ of Todd-Hewitt Broth (THB; Oxoid) in screw-capped culture tubes incubated for $24 \mathrm{~h}$ at $35^{\circ} \mathrm{C}$ 
and $1 \mathrm{ml}$ of culture from each tube was transferred to another THB and incubated for $24 \mathrm{~h}$. Cultures were centrifuged in an 'EBA 12' bench microcentrifuge (Hettich, Tuttlingen, Germany) at $22000 \mathrm{~g}$ for $5 \mathrm{~min}$. Culture supernates were collected aseptically, filtered through a $0.2-\mu \mathrm{m}$ pore size filter (A crodisc 32, Gelman Sciences, Ann Arbor, MI, USA) and then stored at $-70^{\circ} \mathrm{C}$ until analysed. Citrated human blood was washed three times with PBS and used within 1 week of collection. Spectrophotometric analysis was performed with $150 \mu \mathrm{l}$ of an erythrocyte suspension (5\% $\mathrm{v} / \mathrm{v}$ in $\mathrm{PBS}$ ) and an equal volume of culture supernate in sealed Eppendorf tubes. The reaction mixtures were incubated in a water bath at $37^{\circ} \mathrm{C}$ for $1 \mathrm{~h}$ with frequent inversion of the tubes. The reaction was stopped by centrifugation at $22000 \mathrm{~g}$ for $5 \mathrm{~min}$, and $200 \mu \mathrm{l}$ of the reaction mixture were transferred to a flat-bottomed microtitration plate (Hospidex, Nieuwkoop, The Netherlands). The released haemoglobin was measured at $540 \mathrm{~nm}$ with a Novopath microplate reader (BioRad, North Yorkshire). All assays were performed in duplicate and corrected for turbidity of the culture supernate and non-specific haemolysis due to the THB.

For further characterisation of haemolytic activity against human RBC, spectrophotometric assays were performed on supernates from four strains which were diluted in PBS until they displayed an optical density at $540 \mathrm{~nm}\left(O \mathrm{D}_{540}\right)$ between 0.600 and 0.800 . The supernates were incubated with cysteine- $\mathrm{HCl}$ (M erck, Darmstadt, Germany; final concentration $15 \mathrm{~mm}$ ), DTT (dithiothreitol, M erck; concentrations 2, 10 and $50 \mathrm{~mm}$ ), DNTB (5.5'-dithio-bis-(2-nitrobenzoic acid), Sigma; 0.2, 1 and $5 \mathrm{~mm}$ ), $\mathrm{H}_{2} \mathrm{O}_{2}$ (M erck; 0.09, 0.018 and $0.36 \% \quad \mathrm{~V} / \mathrm{v}$ ) and proteinase $\mathrm{K}$ (Boehringer $M$ annheim, M annheim, Germany; 10 and $100 \mu \mathrm{g} / \mathrm{ml}$ ). Results were corrected for solvent effects. A dditionally, the culture supernates were heated at $100^{\circ} \mathrm{C}$ for $15 \mathrm{~min}$. Finally, the RBC were pre-incubated with trypsin (ICN Biomedicals, Costa Mesa, CA, USA; concentrations $0.1,1.0$ and $10 \mathrm{mg} / \mathrm{ml}$ ), washed twice with PBS and then used in the haemolytic assay.

Total 16S rRNA sequencing and reverse line blot hybridisation

For further characterisation to $16 \mathrm{~S}$ rRNA level, isolates were retrieved onto blood agar base (Oxoid) with sheep blood $5 \% \mathrm{v} / \mathrm{v}$, checked for purity and streaked on secondary plates. The cells were transferred to a microcentrifuge tube and spun twice, first in a 100- $\mu$ l volume and then in a $900-\mu \mathrm{l}$ volume of $10 \mathrm{~mm}$ Tris, $150 \mathrm{~mm} \mathrm{NaCl}$ buffer, $\mathrm{pH}$ 8.0. The supernate was discarded and the cells were resuspended in $100 \mu \mathrm{l}$ of TE buffer ( $10 \mathrm{~mm}$ Tris- $\mathrm{HCl}, 1 \mathrm{~mm}$ EDTA, pH 8.0) and heated at $99^{\circ} \mathrm{C}$ for $10 \mathrm{~min}$.

Primers corresponding to residues 8-27 (primer 16S8FE) and 1523-1542 (biotin-labelled primer B16S1523 RB) of the Escherichia coli 16S rRNA gene sequence were used to amplify the entire 16S rRNA gene sequence. Amplification was performed in 25- $\mu$ l reaction volumes, in an OmniGene Thermal Cycler (Hybaid Omnigene, Biozym, Landgraaf, The Netherlands). Each sample contained $10 \mathrm{pmol}$ of both primers, 0.25 units of super Taq DNA polymerase (HT Biotechnology, Cambridge) and standard amounts of amplification reagents (200 $\mu \mathrm{M}$ of each deoxynucleoside triphosphate, $50 \mathrm{~mm}$ Tris- $\mathrm{HCl}, \mathrm{pH}$ 9.0, $50 \mathrm{~mm}$ $\mathrm{KCl}, 1.5 \mathrm{mM} \mathrm{M} \mathrm{gCl} 2$, gelatin $0.01 \%$, Triton $\mathrm{X}-100$ $0.1 \%)$. A $25-\mu$ l overlay of sterile mineral oil was added to the tubes. The PCR programme used was $3 \mathrm{~min}$ at $95^{\circ} \mathrm{C}$, followed by 25 cycles of amplification that consisted of $20 \mathrm{~s}$ at $95^{\circ} \mathrm{C}, 30 \mathrm{~s}$ at $55^{\circ} \mathrm{C}$ and $30 \mathrm{~s}$ at $72^{\circ} \mathrm{C}$.

Fluorescence-labelled dideoxynucleotide technology was used for DNA sequencing reactions (Perkin-Elmer, Applied Biosystems Division, Gouda, The Netherlands). PCR products were purified with Qiaquick PCR purification kits (Qiagen, Hilden, Germany). Sequence reactions were analysed on an $A B I 377$ automated DNA sequencer (Perkin-Elmer). Sequencing was performed with various 16S rRNA specific primers. The collected sequences were assembled, edited and analysed with the DNAStar package (DNA Star, M adison, WI, USA).

The PCR-amplified 16S ribosomal RNA genes were hybridised with 5'-amino-linked oligonucleotide probes (Isogen Bioscience, $M$ aarssen, The Netherlands) directed to the species-specific positions of $\mathrm{S}$. intermedius ATCC $27335^{\top}$ and S. constellatus ATCC $28223^{\top}$. The sequences of these probes are listed in Table 1. Hybridisation reactions were performed by a reverse line blot (RLB) assay as described by K aufhold and coworkers [15]. Oligonucleotide probes were covalently linked to an activated Biodyne $C$ membrane (Pall Filtron, Breda, The Netherlands) by the $5^{\prime}$-amino-group link. For this purpose, the membrane was activated by incubation for $15 \mathrm{~min}$ in 1-ethyl-3-(3-dimethyl-aminopropyl)-carbodiimide (Sigma) 16\%, rinsed with water and placed in a miniblot system (Immunetics, Cambridge, MA, USA). Slots were filled with $150 \mu \mathrm{l}$ of an oligonucleotide suspension, which consisted of (depending on the probe) $50-1600 \mathrm{pmol}$ of oligonucleotide probe in $500 \mathrm{mM} \mathrm{NaHCO} 3, \mathrm{pH}$ 8.4. After incubation for $1 \mathrm{~min}$, excess solution was aspirated, and the blot was removed and inactivated by incubation with $100 \mathrm{~mm} \mathrm{NaOH}$ for $10 \mathrm{~min}$ in a rolling bottle. The blot was then washed with $150 \mathrm{ml}$ of $2 \times$ SSPE ( $360 \mathrm{~mm} \mathrm{NaCl}, 20 \mathrm{~mm} \mathrm{NaH}_{2} \mathrm{PO}_{4}, * \mathrm{H}_{2} \mathrm{O} 2 \mathrm{~mm}$ EDTA, $\mathrm{pH}$ 7.2) sodium dodecyl sulphate (SDS) $0.1 \% \mathrm{w} / \mathrm{v}$, for $5 \mathrm{~min}$ at $60^{\circ} \mathrm{C}$. For hybridisation, the filter was again mounted into the miniblot in a $90^{\circ}$ rotated position, resulting in a perpendicular position of the slots on the lines which contained the oligonucleotide probes. The slots were filled with $150 \mu \mathrm{l}$ of heat-denatured biotinylated PCR products $(10 \mu \mathrm{l}$ of the amplification product in $140 \mu \mathrm{l}$ of $2 \times \mathrm{SSPE}-\mathrm{SDS} 0.1 \% \mathrm{w} / \mathrm{v}$ heated 
Table 1. Oligonucleotide sequences of primers and probes used in PCR and reverse line blot assay

\begin{tabular}{|c|c|c|c|}
\hline Designation & Target specificity & Nucleotide sequence & $\begin{array}{l}\text { Position in } \\
\text { 16S rRNA gene }\end{array}$ \\
\hline $\begin{array}{l}\text { Primers for PCR } \\
\text { 16S8FE } \\
\text { B-16S1523 RB }\end{array}$ & $\begin{array}{l}\text { Eubacterial } 16 \mathrm{~S} \text { rRNA gene } \\
\text { Eubacterial } 16 \mathrm{~S} \text { rRNA gene }\end{array}$ & $\begin{array}{l}\text { GGA ATT CAG AGT TTG ATC MTG GYT CAG } \\
\text { 5'-Biotin-CGG GAT CCA AGG AGG TGA TCC ADC CVC A }\end{array}$ & $\begin{array}{c}8-27 \\
1523-1542\end{array}$ \\
\hline $\begin{array}{l}\text { A mino-linked olig } \\
\text { Con } 210 \\
\text { Con } 280 \\
\text { Con } 1030 \\
\text { Int } 210 \\
\text { Int } 280 \\
\text { Int } 1030\end{array}$ & $\begin{array}{l}\text { lucleotide probes for reverse lin } \\
\text { S. constellatus ATCC } 27823^{\top} \\
\text { S. constellatus ATCC } 27823^{\top} \\
\text { S. constellatus ATCC } 27823^{\top} \\
\text { S. intermedius ATCC } 27335^{\top} \\
\text { S. intermedius ATCC } 27335^{\top} \\
\text { S. intermedius ATCC } 27335^{\top}\end{array}$ & $\begin{array}{l}\text { lotting } \\
\text { 5'-amino-link GTG CAA GAG CAT CAC TAC } \\
\text { 5'-amino-link GCT CAC CAA GGC AAC G } \\
\text { 5'-amino-link TCG GGG CAG AGG TGA } \\
\text { 5'-amino-link GTG CAA ATG CAT CAC TAC } \\
\text { 5'-amino-link GCT CAC CTA GGC GAC } \\
\text { 5'-amino-link TCG GTA CAT CGG TGA CA }\end{array}$ & $\begin{array}{c}229-246 \\
288-303 \\
1052-1066 \\
229-246 \\
288-303 \\
1053-1069\end{array}$ \\
\hline
\end{tabular}

at $99^{\circ} \mathrm{C}$ for $10 \mathrm{~min}$ and chilled on ice) and incubated at $42^{\circ} \mathrm{C}$ for $60 \mathrm{~min}$. A fterwards, the slots were aspirated and the blot was removed from the miniblotter and washed twice at $52^{\circ} \mathrm{C}$ for $10 \mathrm{~min}$ with $2 \times$ SSPE-SDS $0.5 \% \mathrm{w} / \mathrm{v}$. The membranes were incubated with streptavidin-peroxidase conjugate (Boehringer $\mathrm{M}$ annheim, Mannheim, Germany; diluted 1 in 4000) at $42^{\circ} \mathrm{C}$ for $45 \mathrm{~min}$ in $10 \mathrm{ml}$ of $2 \times \mathrm{SSPE}-\mathrm{SDS} 0.5 \% \mathrm{w} / \mathrm{v}$ and then washed twice (10 min each) with $150 \mathrm{ml}$ of $2 \times$ SSPE-SDS $0.5 \% \mathrm{w} / \mathrm{v}$ at $42^{\circ} \mathrm{C}$. A fter a final $5-\mathrm{min}$ wash step with $2 \times \mathrm{SSPE}$, the membranes were incubated with ECL detection reagents (A mersham International, 's Hertogenbocsch, The Netherlands) for $1 \mathrm{~min}$ and used to expose an ECL hyperfilm (A mersham) for $10 \mathrm{~min}$ to visualise hybridisation. A fter each hybridisation and detection step, the PCR products were stripped from the membrane by washing it twice in SDS $1 \% \mathrm{w} / \mathrm{v}$ at $80^{\circ} \mathrm{C}$ for $30 \mathrm{~min}$ and thereafter the blot was incubated in $20 \mathrm{~mm}$ EDTA, pH 8.0, sealed moist in plastic and stored at $4^{\circ} \mathrm{C}$ until re-used.

\section{Statistical analysis}

For statistical evaluation, proportions were compared by the $\chi^{2}$ test.

\section{Nucleotide sequences and accession numbers}

The sequences of the strains investigated in the study are available from Gen-Bank under the following accession numbers: S. intermedius ATCC 27335, AF104671; S. intermedius EHH strain no. 125,
AF104672; S. intermedius EHH strain no. 488, AF104673; S. intermedius non-EHH strain no. 535 , AF104674; S. intermedius non-EHH strain no. 539, AF104675, S. constellatus ATCC 27823, AF104676; S. constellatus strain no. 206, AF104677; S. anginosus ATCC 33397, A F104678; S. anginosus strain no. 1012, AF 1046679.

\section{Results}

Detection and characterisation of haemolytic activities, phenotypic and clinical characteristics of the strains

A total of 297 strains was included in the study. Table 2 presents the results of both the 16S rRNA genotype and the phenotype in relation to each other. Table 3 displays the haemolytic activities of the SM $G$ strains (identified as $16 \mathrm{~S}$ rRNA genotypes and phenotypes) against human and animal RBC, and the oligonucleotide probes to which the strains hybridised in the RLB assay.

When screened by the quantitative plate method, 124 strains produced $\beta$-haemolysis on sheep blood agar and 173 strains did not. With the exception of a few discrepancies, the results of the haemolysis on sheep blood agar were identical to those obtained on agar with RBC from cow, horse, pig and rabbit. The haemolytic pattern of the strains that lysed animal blood was similar for the RBC of all animal species tested: a zone of haemolysis that was best discernible on bright light transmission underneath a glass plate

Table 2. Comparison of phenotype and $16 \mathrm{~S}$ rRNA genotype of SM G strains

\begin{tabular}{|c|c|c|c|c|}
\hline \multirow[b]{2}{*}{ Phenotype* } & \multicolumn{3}{|c|}{ Number of strains identified to the genotype ${ }^{\dagger}$} & \multirow[b]{2}{*}{ Total } \\
\hline & S. anginosus & S. constellatus & S. intermedius & \\
\hline $\begin{array}{l}\text { S. anginosus } \\
\text { S. constellatus } \\
\text { S. intermedius }\end{array}$ & $\begin{array}{r}101 \\
0 \\
0\end{array}$ & $\begin{array}{r}1 \\
113 \\
7\end{array}$ & $\begin{array}{r}0 \\
22 \\
53\end{array}$ & $\begin{array}{r}102 \\
135 \\
60\end{array}$ \\
\hline Total & 101 & 121 & 75 & 297 \\
\hline
\end{tabular}


Table 3. Haemolytic activities of strains with distinct $16 S$ rRNA genotypes against RBC of animal and human origin

\begin{tabular}{|c|c|c|c|c|}
\hline \multirow{2}{*}{$\begin{array}{l}\text { 16S rRNA genotype and } \\
\text { designation }\end{array}$} & \multicolumn{2}{|c|}{ Haemolysis on blood agar plate } & \multirow[b]{2}{*}{ Probes that hybridised in RLB } & \multirow[b]{2}{*}{ Phenotype } \\
\hline & A nimal & Human & & \\
\hline S. anginosus (101) & $\begin{array}{l}\text { Narrow zone }(25) \\
\text { No haemolysis }(76)\end{array}$ & $\begin{array}{l}\text { Narrow zone (25) } \\
\text { No haemolysis }(76)\end{array}$ & ND & S. anginosus (101) \\
\hline S. constellatus (121) & $\begin{array}{l}\text { Narrow zone }(74) \\
\text { No haemolysis }(47)\end{array}$ & $\begin{array}{l}\text { Narrow zone (74) } \\
\text { No haemolysis (47) }\end{array}$ & $\begin{array}{l}\text { Con 210, Con 280, Con } 1030 \\
\text { (121) }\end{array}$ & $\begin{array}{l}\text { S. anginosus ( } 1 \text { ) } \\
\text { S. constellatus (113) } \\
\text { S. intermedius ( } 7 \text { ) }\end{array}$ \\
\hline S. intermedius EHH strains (49) & $\begin{array}{l}\text { Narrow zone }(1) \\
\text { No haemolysis }(48)\end{array}$ & $\begin{array}{l}\text { Large zone }(1) \\
\text { Large zone }(48)\end{array}$ & Int 210, Int 280, Int 1030 & S. intermedius (49) \\
\hline $\begin{array}{l}\text { S. intermedius non-EHH } \\
\text { strains (26) }\end{array}$ & $\begin{array}{l}\text { Narrow zone }(24) \\
\text { No haemolysis (2) }\end{array}$ & $\begin{array}{l}\text { Narrow zone (24) } \\
\text { No haemolysis (2) }\end{array}$ & $\begin{array}{l}\text { Int 210, Con 280, Con } 1030 \\
(26)\end{array}$ & $\begin{array}{l}\text { S. constellatus (22) } \\
\text { S. intermedius (4) }\end{array}$ \\
\hline
\end{tabular}

$\mathrm{ND}$, not done; ( ), number of strains.

and did not extend $>2 \mathrm{~mm}$ outside the colony edge. This pattern was shared by strains that belonged to all three $16 \mathrm{~S}$ rRNA genotypes. For strains belonging to the $\mathrm{S}$. anginosus and S. constellatus $16 \mathrm{~S}$ rRNA genotypes, the results of the haemolysis on human blood agar plates were identical to those obtained on animal blood agar. In contrast, 48 strains belonging to the $\mathrm{S}$. intermedius 16S rRNA genotype displayed no haemolysis on animal blood agar, but showed haemolysis on human blood agar. Their haemolytic pattern on human blood agar appeared as a clear, sharply delineated, distinctly large zone, that often reached up to $3 \mathrm{~mm}$ outside the edge of the colony. A single $S$. intermedius strain showed a narrow zone of haemolysis on animal blood agar, but displayed a large zone of haemolysis on human blood agar. This strain was grouped together with the 48 strains that did not show any detectable zone of haemolysis on animal blood agar. These 49 strains were designated ' $S$. intermedius exclusive human haemolytic' strains (S. intermedius EHH strains) and included the S. intermedius ATCC 27335 type strain. The remaining $26 \mathrm{~S}$. intermedius strains were designated ' $S$. intermedius non- $E H H$ ' strains. Of these $\mathrm{S}$. intermedius non-EHH strains, 24 displayed a narrow zone of haemolysis on the animal blood agar and two strains did not affect RBC of any species tested.

In the quantitative assay for haemolysis of human $R B C$, all $S$. intermedius $E H H$ strains had $O D_{540}$ units
$>0.550$, whereas the $S$. intermedius non-EHH strains, as well as control strains belonging to $\mathrm{S}$. anginosus (14) and S. constellatus (18), did not show any detectable haemolytic activity.

In the phenotypic identification method, all the $\mathrm{S}$. intermedius EHH strains correlated with the $S$. intermedius phenotype. In contrast, the majority (22 of 26) of the $S$. intermedius non-EHH strains were characterised phenotypically as $\mathrm{S}$. constellatus and thus accounted for the identification mismatch between the $\mathrm{S}$. intermedius genotype and phenotype that is apparent from Table 2. In terms of individual phenotypic identification reactions, the $\mathrm{S}$. intermedius $\mathrm{EHH}$ strains invariably displayed neuraminidase, $\beta$-D-N-acetylgalactosaminidase and $\beta$-D-N-acetylglucosaminidase enzyme activities, whereas the majority of the $S$. intermedius non-EHH strains $(23,23$ and 25 strains, respectively) did not $(p<0.001)$.

A mongst the patients from whom the $S$. intermedius EHH strains were isolated, a male:female ratio of 5.6:1 was observed. The S. intermedius EHH strains were significantly more frequently associated with abscessand infection-related samples than the $\mathrm{S}$. intermedius non-EHH strains (Table 4). They were proportionally (but not significantly) recovered more frequently from the abdomen, the head and neck region, skin, soft tissues and the blood.

Table 4. Male:female ratio of the patients from whom the SMG strains were isolated and clinical significance of the samples from which the SMG strains were isolated*

\begin{tabular}{llcr}
\hline & & \multicolumn{2}{c}{ Number of strains that were } \\
\cline { 3 - 4 } 16S rRNA genotype and designation & Male:female ratio & $\begin{array}{c}\text { Abscess- or } \\
\text { infection-related }\end{array}$ & $\begin{array}{c}\text { Questionable clinical } \\
\text { significance }\end{array}$ \\
\hline S. intermedius EHH strains & $5.6: 1(p<0.001)$ & 46 & $2(p<0.001)$ \\
S. intermedius non-EHH strains & $1.2: 1$ & 8 & 18 \\
S. constellatus & $1.4: 1$ & 68 & 52 \\
S. anginosus & $0.7: 1$ & 49 & 51 \\
\hline
\end{tabular}

*ATCC type strains were omitted from the comparison. 
A naerobic incubation did not enhance the haemolytic activity of the $\mathrm{S}$. intermedius $\mathrm{EHH}$ strains against human RBC, and no increase in haemolysis against human RBC was found after hot rather than cold incubation. In the qualitative assay of haemolysis against human RBC, the haemolytic activities of the culture supernates of the $S$. intermedius $E H H$ strains were not affected by DNTB and DTT, and not enhanced by incubation with cysteine- $\mathrm{HCl}$. A fter heating at $100^{\circ} \mathrm{C}$, the haemolytic activity of the culture supernates was completely abolished. Trypsinisation of the $R B C$ resulted in a decrease of haemolytic activity, with total loss of haemolysis at the final concentration of $10 \mathrm{mg} / \mathrm{ml}$. Phospholipase activity was not detected in any of the 60 strains tested (20 strains of each SM G species were tested).

\section{Determination of $16 \mathrm{~S}$ rRNA sequence and reverse} line blotting

The nearly complete 16S rRNA sequences of the three ATCC strains, two $S$. intermedius EHH strains, two $S$. intermedius non-EHH strains and a randomly chosen $\mathrm{S}$. anginosus and $\mathrm{S}$. constellatus strain were determined. Fig. 1 shows the genetic distances and a phylogenetic tree sequence similarity of these sequences. The $S$. intermedius $\mathrm{EHH}$ strains had $\geqslant 99.9 \%$ sequence similarity with S. intermedius strain ATCC $27335^{\top}$.
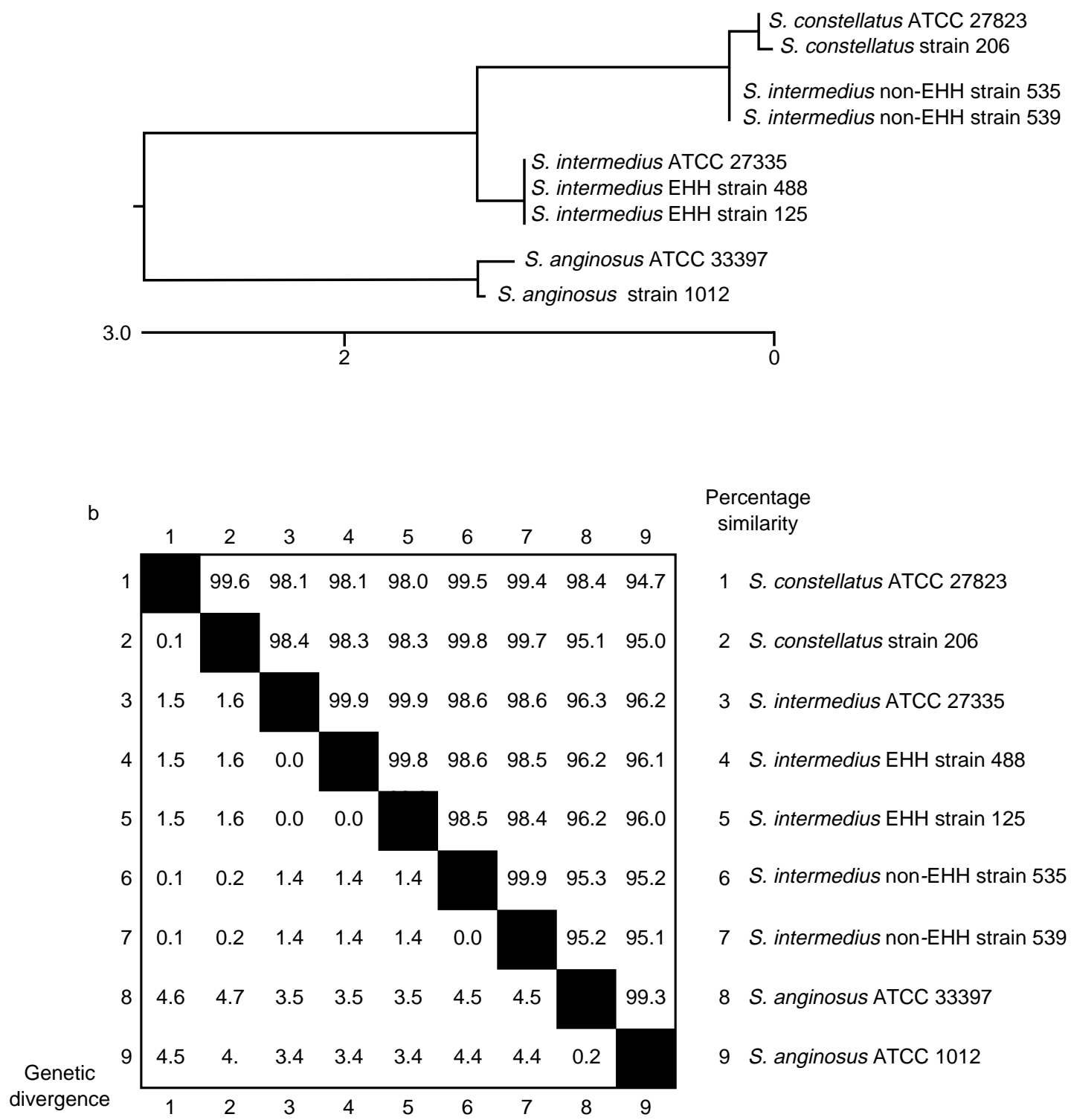

Percentage

similarity

1 S. constellatus ATCC 27823

2 S. constellatus strain 206

3 S. intermedius ATCC 27335

4 S. intermedius $\mathrm{EHH}$ strain 488

5 S. intermedius $\mathrm{EHH}$ strain 125

6 S. intermedius non-EHH strain 535

7 S. intermedius non-EHH strain 539

8 S. anginosus ATCC 33397

9 S. anginosus ATCC 1012

Fig. 1. Genetic relationships among the ATCC type strains S. anginosus 33397, S. constellatus 27823 and S. intermedius 27335, two $S$. intermedius EHH strains, two $S$. intermedius non-EHH strains and a randomly chosen strain each of S. anginosus and S. constellatus. Results are based on the comparison of the virtually complete 16S rR NA gene sequences (1523 bp). (a) Unrooted phylogenetic tree showing the inter-relationships between the different strains. (b) Levels of relatedness of the different strains. 
The 16S rRNA gene sequences of the $S$. intermedius non-EHH strains shared the sequences of $S$. constellatus strain ATCC $27823^{\top}$ except for positions 228 and 229 that carried an $\mathrm{S}$. intermedius signature sequence. The $S$. intermedius non-EHH strains were most closely related to the $S$. constellatus strains, showing a $16 S$ rRNA sequence similarity with the $S$. constellatus and S. intermedius type strains of $99.5 \%$ and $98.6 \%$, respectively. RLB hybridisation with the oligonucleotide probes demonstrated genotypic homogeneity within the S. intermedius $\mathrm{EHH}$ strains and the $\mathrm{S}$. intermedius non-EHH strains, respectively. The $S$. intermedius EHH strains reacted invariably with the three $\mathrm{S}$. intermedius probes, whereas the $\mathrm{S}$. intermedius non-EHH strains hybridised with the 229-246 S. intermedius probe and with the 288-303 and the 1052-1066 S. constellatus probes (Table 2).

\section{Discussion}

This study investigated the haemolytic activity of 297 SMG strains against RBC from man and various animal species. It demonstrated that some of the strains belonging to the $S$. intermedius $16 \mathrm{~S}$ rRNA genotype (S. intermedius $\mathrm{EHH}$ strains) produced haemolytic activity restricted to human $R B C$, whereas others did not ( $S$. intermedius non-EHH strains).

Although the study did not attempt to isolate the enzyme responsible for the haemolytic activity, the pattern of haemolysis of the $\mathrm{S}$. intermedius $\mathrm{EHH}$ strains on human blood agar, together with the physiological properties of the haemolytic activities of the culture supernates, indicated that intermedilysin was the enzyme involved in haemolysis. According to Nagamune and co-workers, the most distinctive property of intermedilysin is its animal species specificity, as only human RBC were lysed by the enzyme [11]. In the present study, this particular characteristic was used to screen a collection of SMG strains. In agreement with the findings of Nagamune and co-workers, the haemolytic activity of the culture supernates in this study was heat-labile and was not influenced by either reducing or oxidising agents, precluding the possibility of a thiol-activated enzyme. Furthermore, none of the strains examined was active against lecithin, which suggested that the haemolysin did not fall into the phospholipase category of membrane-damaging haemolysins. Consequently, it may be concluded that intermedilysin activity is confined to the $S$. intermedius species as defined by both the complete 16S rRNA sequence and by the presence of neuraminidase, $\beta$-D-Nacetylgalactosaminidase and $\beta$-D-N-acetylglucosaminidase enzymes.

The relationship between abscess- and infection-related clinical samples on the one hand and the presence of $S$. intermedius EHH strains on the other suggested that the haemolysis of human RBC may be a factor in pathogenicity. Further studies with defined mutants, deficient in haemolytic activities, are necessary to obtain direct evidence for the pathogenic nature of the haemolytic activity.

M ost diagnostic laboratories use sheep or horse blood agar to screen for haemolysis and this may explain the paradoxical fact that non-haemolytic SM G strains have been found to be more associated with purulent infections than the $\beta$-haemolytic SMG strains $[8,9]$. Indeed, from the present data, many of the non-(sheep) haemolytic SMG strains encountered in diagnostic practice represented $\mathrm{S}$. intermedius strains that invariably expressed haemolysis against human RBC without affecting animal RBC. Furthermore, in diagnostic laboratories, $\beta$-haemolytic streptococci are investigated in detail more frequently than are non-haemolytic streptococci [4]. For this reason, the real incidence of $\mathrm{S}$. intermedius in clinical samples might have been underestimated. According to the present findings, the lysis of human RBC could be explored as a possible taxonomic property and it may be used as a valuable diagnostic tool to facilitate recognition of $S$. intermedius strains among the accompanying flora in clinical samples.

This study used RLB to hybridise the SM G strains with oligonucleotide probes tailored to recognise sequences that were determined by sequencing the complete $16 \mathrm{~S}$ rRNA genes of a panel of representative strains. The key feature of RLB in this setting was its ability to screen a large number of strains, omitting the need to sequence them. Furthermore, RLB offered additional advantages: only small amounts of PCR products were needed, the different probes could be hybridised concurrently and the blots with the covalently linked probes could be re-used, resulting in a 'labour-friendly' and standardised system. The genotypic identification results for the $S$. intermedius and $S$. constellatus strains in the present study differed in part from the results of the previous study (Table 2) [5]. However, in the previous study, sequence relatedness was calculated on only part of the 16S rRNA gene (i.e., position 0 - 487) and a diagnostic probe for identification was constructed complementary to part of this sequence (i.e., position 213-231). In contrast, in the present study the complete 16S rRNA gene was used for comparison. Genotypic identification based on the total 16S rRNA gene as presently performed resulted in a higher agreement with the phenotypic identification method, in particular because the majority (22 of 26) of the $S$. intermedius non-EHH strains (that phenotypically behave as $\mathrm{S}$. constellatus) were identified as $\mathrm{S}$. constellatus whereas in the previous study they were assigned to the $S$. intermedius $16 \mathrm{~S}$ rRNA genotype.

In terms of $16 \mathrm{~S}$ rRNA gene relatedness, phenotypic identification and haemolytic activity, the S. intermedius $E H H$ strains were identical to $S$. intermedius strain ATCC $27335^{\top}$ and, therefore, constitute a single 
species. Additional features that distinguished the $\mathrm{S}$. intermedius strains as a distinct species included their predilection for defined body sites such as the dental plaque as commensals, and liver and brain abscesses as pathogens $[9,10]$. An intriguing but yet unexplained feature documented in this study was the high male:female ratio of the patients from whom the clinical samples containing the $\mathrm{S}$. intermedius $\mathrm{EHH}$ strains were recovered. Most of these samples were associated with purulent infection. Reviewing the SM G strains implicated in purulent infections, Gossling also compiled a strong male bias, even if cases associated with trauma or alcoholism were subtracted [3]. Unlike $\mathrm{S}$. intermedius, the $\mathrm{S}$. constellatus species appeared to display genotypic variability, as suggested in a previous report [5]. A similar phenomenon of intra-species diversity has been observed for $S$. anginosus as currently defined, with the existence of distinct phenotypic groups and genomic subgroups at the $16 \mathrm{~S}$ rRNA level $[16,17]$. Based on the close 16S rRNA gene relatedness between the $S$. intermedius non- $E H H$ strains and S. constellatus strain ATCC $27823^{\top}$ as expressed in Fig. 1, we assume that the $\mathrm{S}$. intermedius non-EHH strains should be allocated to the $S$. constellatus species. However, at such high levels of 16S rRNA gene sequence similarities, DNA - DNA reassociation studies are needed to confirm this supposition [18]. Despite the 16S rRNA homogeneity within the $S$. intermedius non-EHH strains, the present study did not find either phenotypic or clinical consistency. Thus, the $S$. intermedius non-EHH strains resemble the previously described $\mathrm{Cl}$ strains that were considered to be a distinct rRNA population for which phenotypic and clinical significance remained to be determined [5]. At present, further studies are being conducted to investigate the relationships between the $S$. intermedius non- $\mathrm{EHH}$ strains, the $\mathrm{Cl}$ strains and the $\mathrm{S}$. constellatus strains.

In conclusion, the present study demonstrated that, within the SMG, haemolysis of human RBC was confined to the $S$. intermedius strains. Circumstantial evidence indicated that intermedilysin was the putative factor for haemolysis and further emphasised the role of this enzyme in pathogenicity. A nalysis of the total 16S RRNA gene and RLB with specific oligonucleotide probes resulted in a better delineation of the $S$. intermedius 16S rRNA genotype and in the identification of a distinct 16S rRNA population that encompassed strains most closely related to $\mathrm{S}$. constellatus ATCC $27823^{\top}$. Further studies are needed to provide direct evidence that the haemolytic activity against human RBC is a virulence factor, and to elucidate the genotypic variability within the $\mathrm{S}$. constellatus species.

We thank Dr R. A. Whiley, St Bartholomew's and the Royal London Hospital School of Medicine and Dentistry, London, and Dr J. D. A . van Embden, National Institute of Public Health and the Environment for critical reading of the manuscript.

\section{References}

1. Kawamura $Y$, Hou XG, Sultana F, Miura H, Ezaki $T$. Determination of $16 \mathrm{~S}$ rRNA sequences of Streptococcus mitis and Streptococcis gordonii and phylogenetic relationships among members of the genus Streptococcus. Int J Syst Bacteriol 1995; 45: 406-408.

2. Whiley RA, B eighton D. Emended descriptions and recognition of Streptococcus constellatus, Streptococcus intermedius, and Streptococcus anginosus as distinct species. Int J Syst Bacteriol 1991; 41: 1-5.

3. Gossling J. Occurrence and pathogenicity of the Streptococcus milleri group. Rev Infect Dis 1988; 10: 257-285.

4. Ruoff KL. Streptococcus anginosus ('Streptococcus milleri'): the unrecognized pathogen. Clin Microbiol Rev 1988; 1: $102-108$.

5. Jacobs JA, Schot CS, Bunschoten AE, Schouls LM. Rapid species identification of 'Streptococcus milleri' strains by line blot hybridization: identification of a distinct 16S rRNA population closely related to Streptococcus constellatus. J Clin Microbiol 1996; 34: 1717-1721.

6. Kambal AM. Isolation of Streptococcus milleri from clinical specimens. J Infect 1987; 14: 217-223.

7. Spertini $F$, Baumgartner JD, Bille J. [Clinical spectrum of a common and insidious pathogen: Streptococcus milleri.] Spectre clinique d'un pathogène commun et insidieux: le Streptococcus milleri. Schweiz Med Wochenschr 1988; 118: 1393- 1397

8. Van der Auwera P. Clinical significance of Streptococcus milleri. Eur J Clin Microbiol 1985; 4: 386-390.

9. Jacobs JA, Pietersen $H G$, Stobberingh $E E$, Soeters $P B$. Streptococcus anginosus, Streptococcus constellatus and Streptococcus intermedius: Clinical relevance, hemolytic and serologic characteristics. Am J Clin Pathol 1995; 104: 547- 553.

10. Whiley RA, Beighton D, Winstanley TG, Fraser HY, Hardie JM. Streptococcus intermedius, Streptococcus constellatus, Streptococcus anginosus (the Streptococcus milleri group): association with different body sites and clinical infections. J Clin Microbiol 1992; 30: 243-244.

11. Nagamune H, Ohnishi $\mathrm{C}, \mathrm{K}$ atsuura $\mathrm{A}$ et al. Intermedilysin, a novel cytotoxin specific for human cells, secreted by Streptococcus intermedius UNS46 isolated from a human liver abscess. Infect Immun 1996; 64: 3093-3100.

12. Whiley RA, Fraser $H$, Hardie JM, Beighton D. Phenotypic differentiation of Streptococcus intermedius, Streptococcus constellatus, and Streptococcus anginosus strains within the 'Streptococcus milleri group'. I Clin Microbiol 1990; 28 1497- 1501

13. Smith RF, Willett NP. Rapid plate method for screening hyaluronidase and chondroitin sulfatase-producing microorganisms. Appl Microbiol 1968; 16: 1434-1436.

14. Garner JS, Jarvis WR, Emori TG, Horan TC, Hughes JM. CDC definitions for nosocomial infections 1988. Am J Infect Control 1988; 16: 128-140.

15. Kaufhold A, Podbielski A, Baumgarten G, Blokpoel M, Top J, Schouls LM. Rapid typing of group A streptococci by the use of DNA amplification and non-radioactive allele-specific oligonucleotide probes. FEMS Microbiol Lett 1994; 119: 19-26.

16. Bergman S, Selig M, Collins MD et al. 'Steptococcus milleri' strains displaying a gliding type of motility. Int J Syst Bacteriol 1995; 45: 235-239.

17. Whiley RA, Hall LMC, Hardie JM, Beighton D. Genotypic and phenotypic diversity within Streptococcus anginosus. Int J Syst Bacteriol 1997; 47: 645-650.

18. Stackebrandt E, Goebel BM. Taxonomic note: a place for DNA - DNA reassociation and 16S rRNA sequence analysis in the present species definition in bacteriology. Int J Syst Bacteriol 1994; 44: 846-849. 